\section{Gorilla conservation programme suffers setback}

The International Gorilla Conservation Programme (IGCP), a partnership between FFI, the African Wildlife Foundation and World Wide Fund for Nature-International, has been dealt a severe blow. On 13 August a male silverback mountain gorilla, Rugabo, and an adult female were shot dead by poachers in the Virunga National Park in Zaire a few hours after tourists had visited their group. The reason for the killings did not become apparent until several days later when a $2^{1 / 2-}$ year old gorilla was found in a field close to the Ugandan border. The women who found the gorilla reported it, and the Institut Zairois pour la Conservation de la Nature (IZCN) was alerted. The gorilla was captured and, on the assumption that poachers had captured it from Rugabo's group and then abandoned it, IZCN and IGCP staff started a careful operation to return it. It was difficult to approach Rugabo's group, which had become extremely shy since the killings and initially fled at the approach of humans but, eventually tourist guides who were familiar with the group were able to approach with the young gorilla. On opening the transport cage the young male emerged, walked towards its kin and was immediately accepted.

While the successful reintroduction of the young captive provided a heartening moment for IGCP and IZCN personnel, the killings give cause for great concern. The deaths came only a week after the silverback Salama was found dead in the Bukima area of Zaire, one month after he had been reported missing. While the cause of death could not be confirmed, it is believed that he died either in a fight with another silverback, which would be unusual, or was killed by poachers. In March four gorillas from the 18-strong Kyaguliro group, which was being habituated for research purposes, in the Bwindi Forest, Uganda, were killed with spears.

As we went to press we recieved news that another silverback, Luwawa, was shot in Zaire on 29 August. His group, which was also habituated for tourists, has fled and it is not known whether any infants were taken.

Eight gorilla deaths in 5 months in a total population of only just over 600 is a significant loss, especially where the deaths involve silverbacks. The loss of a group leader often leads to social disruption and readjustment; the leaderless group may merge with another and this can lead to the death of infants.

For 10 years the IGCP (which evolved from the Mountain Gorilla Project set up in 1979) was pleased to report that not one mountain gorilla was known to have been killed by poachers. The efforts of the programme, the commitment to the conservation of the gorillas and their habitat by the governments of Rwanda, Uganda and Zaire, and the dedication of IGCP and protected-area personnel seemed to be paying off. Before the outbreak of the war in Rwanda the gorillas' future had looked secure. It is sobering to realise how rapidly situations can change for the better, or for the worse. In 1984 Roger Wilson, then field officer for the Mountain Gorilla Project, wrote from Rwanda; 'Five years into the project the fight against poaching is in full swing...The anti-poaching effort must be extended...There is going to be a lot of hard, grinding work before anyone can say that poaching is not the major cause of concern' (Oryx, 18 (4), 223-229).

The peace of a decade has been shattered and the IGCP has some tough decisions to make about how best to tackle the new outbreak of poaching. The war has resulted in many displaced, desperate people: well-organized poaching syndicates are only too ready to enlist their help in the quest for endangered animals. While it is vital that protection efforts are increased - and IGCP will do all it can in this respect - the battle cannot be fought only on the front line. The demand for mountain gorillas from irresponsible zoos and wealthy individuals, principally in the Far East, appears to be the driving force behind the poaching. A way has to be found to address that problem: the desire to own endangered species may be a hard one to quench but it must be done if IGCP's efforts are not to be in vain.

Jacqui Morris Editor 